\title{
APORTES PARA EL CICLO DE FORMACIÓN COMÚN DE LOS PROFESORADOS EN HISTORIA Y GEOGRAFÍA EN EL SISTEMA EDUCATIVO ARGENTINO La renovación historiográfica y las categorías territoriales en el estudio de la realidad social
}

\author{
Contributions for the Common Training Cycle of Teachers in History and Geography
}

in the Argentine Educational System: The historiographical renovation and the territorial categories

in the study of the social reality

\section{GUSTAVO NORBERTO DUPERRÉ}

Universidad del Salvador, Buenos Aires, Argentina

Dirección General de Cultura y Educación, La Plata, Argentina

\section{KEY WORDS}

Educational Policies

Teacher Training Degree

Social Sciences

Geography; History

Territorial Categories

Historiographical

Renovation

Interdisciplinary Studies

\section{ABSTRACT}

At the end of the 20th century, the Teacher Preparation Program in Argentina experienced a series of changes, as result of the renewal of public policies. In this aspect, teachers in History and Geography, as well as others of different academic orientations, have modified the choice of their contents and the processing of their objects of study, generating new challenges in the different levels of the performance of educators. Considering these processes, the redefinition of territorial categories and historical reality represents a new and a valid alternative to reinterpret social phenomena.

\section{PALABRAS CLAVE}

Políticas educativas Formación Docente de Grado Ciencias Sociales; Geografía Historia

Categorías territoriales Renovación historiográfica Estudios interdisciplinarios

\section{RESUMEN}

Al finalizar el siglo XX, la Formación Docente de Grado en la República de Argentina experimentó una serie de cambios, producto de la renovación de las políticas públicas. En este aspecto, los Profesores en Historia y en Geografía, al igual que otros de distintas orientaciones académicas, han ido modificado la elección de sus contenidos y el tratamiento de sus objetos de estudio, generando nuevos desafíos en los distintos niveles del desempeño de los educadores. Ante estos procesos, la redefinición de las categorías territoriales y la realidad histórica se presenta como una alternativa nueva y válida para reinterpretar los fenómenos sociales.

\section{GLOBAL}




\section{Introducción}

$\mathrm{E}$ $n$ el marco de las políticas educativas implementadas en la República Argentina, la sanción de la Ley de Educación Nacional $N^{\circ}$ 26.206, ha modificado los diferentes apartados curriculares, tanto en el encuadre pedagógico, como así también en el alcance de sus contenidos. Estos reajustes para el Ciclo Básico Común y Superior Orientado de Educación Secundaria se han trasladado indefectiblemente a la Formación Docente de Grado. Por ende, los Institutos Superiores del Profesorado, al ser los ámbitos en los que tiene lugar la preparación profesional de los educadores, se constituyen en los espacios primordiales de articulación entre los niveles educativos implicados.

En el caso específico de los Profesorados en Historia y en Geografía, les compete a ambos, un primer año de formación común, permitiendo a los futuros docentes desempeñarse con idoneidad en la investigación de la realidad social, y la consiguiente profundización en un saber disciplinar, que sea capaz de integrar a los aspectos conceptuales y metodológicos propios de las ciencias histórica y geográfica. Este proceso ha traído consigo el debate respecto a la selección de los contenidos para la enseñanza de las Ciencias Sociales y de Geografía e Historia específicamente. En principio, la renovación historiográfica y las nuevas categorías para el análisis del territorio, se presentan como los principales cambios tendientes a la apertura e interpretación de los fenómenos sociales en su totalidad.

El objetivo de esta contribución consiste en formular un esquema de referencia pedagógico, cuyas relaciones conceptuales articulen el estudio de los procesos históricos y los espacios geográficos, considerando a la complejidad, el conflicto, el cambio y la permanencia como rasgos de la realidad histórica; y a la estructura, el proceso, la función y la forma como categorías clave del análisis territorial. La metodología de investigación es exploratoria y de orientación interdisciplinaria.

\section{Las complejidades en el estudio de la realidad social: desafíos $y$ oportunidades}

La prevalencia de los ejes espacio-tiempo en el estudio de las Ciencias Sociales, ha propiciado que la Geografía y la Historia se encuentren bajo una constante revisión disciplinar. Asimismo, la condición multicausal de los fenómenos sociales ha incrementado nuevos enfoques de interpretación multidisciplinarios, como correlato de la complejidad en que trascurre el mundo contemporáneo.

La renovación en los planteos a los que se hace referencia, se ha proyectado en los centros de formación del Profesorado e incluso se los intenta articular con todos los niveles de enseñanza. Esta dinámica adquiere sus fundamentos al considerar, que: "Los Institutos de Formación Docente (IFD) son, desde el punto de vista social y jurídico, ámbitos legítimos en que se realiza la preparación profesional de los educadores (y que además), el futuro docente se forma en una institución específica pero necesita insertarse en la realidad escolar de las instituciones de los niveles implicados, para poder concretar su preparación como profesional" (Res. $\mathrm{N}^{\circ}$ 13271-99. Modificada por Res. $\mathrm{N}^{\circ} 3581-00,1999$, pp.5-7). Tal nivel de inserción trae consigo un reto, en lo concerniente a la articulación entre la estructura curricular de los campos de estudio (en el recorte que nos convoca: Historia y Geografía), las realidades institucionales y lo que acontece fuera del ámbito pedagógico. Uno de los inconvenientes que derivan en su tratamiento, consiste en la insuficiencia de argumentos al momento de dar una explicación categórica sobre la intrincada vinculación entre los territorios y las sociedades en un momento histórico determinado. En opinión de Feinmann (2011), por ejemplo: "El tiempo ya no es lo temporal, ya no lo entendemos ni lo vivimos como acontecer histórico. Solo es instantaneidad, un vértigo que anula el pensar, un zapping que despierta emociones y las anula enseguida pasando a otro tema, a otra cuestión, a otro lugar del mundo" (p.11). No obstante, "la realidad social produce un impacto en nosotros que nos mueve a profundizar, a desmenuzar, a ampliar y a actualizar nuestros marcos explicativos. (...) Diariamente el investigador o cientista social se replantea los códigos con los cuales analiza y explica dicha realidad" (García, Iaíes y Segal, 1993, p.33). En esa revisión ha tenido que ver seguramente, la inclusión de otras miradas en el seno epistemológico de las propias disciplinas; así: "la historiografía (es decir, la escritura de la historia o los escritos sobre historia) que existe acerca del pasado reciente tiene múltiples escritores, que provienen de diversas disciplinas, no sólo del campo de la historia" (Eggers-Brass, 2012, p.24). Por otro lado, "la esencia de la Geografía, desde su configuración como ciencia moderna hasta nuestros días, se cristaliza en la doble vertiente del estudio del espacio y de las relaciones del ser humano con su ambiente" (Durán, 1996, p.28).

De lo expresado se infiere, que lo que implica una anulación en el acto de pensar en Feinmann (2011) producto del vértigo temporal, puede ser capitalizado positivamente, tras el impacto de la realidad social, instando a la ampliación de nuevos encuadres explicativos al decir de García, Iaíes y Segal (1993). Por consiguiente, interesa señalar aquí, que el desafío trae consigo una dimensión de oportunidad, vista como una acción de abordaje interdisciplinario e integrador, que facilite la comprensión de las dinámicas de la sociedad contemporánea. De acuerdo con esto, "tanto entre los que se dedican al estudio de lo humano y de lo social (...), como entre los epistemólogos que se ocupan del conocimiento producido por aquellos, 
pueden reconocerse tres enfoques totalmente diferentes. Cada uno supone creencias contrapuestas acerca de la naturaleza de las ciencias sociales y de su método" (Klimovsky e Hidalgo, 2012, p.20). Ellos son: 1) El enfoque naturalista, caracterizado por el valor otorgado a las ciencias naturales y formales, como un móvil de logros para las ciencias humanas y sociales; 2) El enfoque interpretativo, mediante el cual se captan y explicitan las razones y motivaciones que se hallan detrás de la acción humana en las diversas sociedades y situaciones históricas peculiares; y 3) La escuela crítica, donde interesa dilucidar como se vincula la investigación con el encuadre político de la sociedad y con la situación social dominante (Klimovsky e Hidalgo, 2012).

No se hará una mayor descripción de los enfoques citados, pero lo que sí es oportuno remarcar, es que cualquiera de ellos son factibles de interacción conjunta, parcialmente $o$ en su totalidad, a fin de explicar acabadamente las problemáticas que involucran a los territorios y a las sociedades en su acontecer histórico. A modo de corolario, De Souza Minayo (2007) afirma:

La realidad social es el propio dinamismo de la vida individual y colectiva con toda la desbordante riqueza de significados. Esa misma realidad es más rica que cualquier teoría, cualquier pensamiento y cualquier discurso que podamos elaborar sobre ella. Por lo tanto, los códigos de las ciencias que por su naturaleza son siempre referidos $y$ recortados son incapaces de contenerla. Las Ciencias Sociales, mientras, poseen instrumentos y teorías capaces de hacer una aproximación de lo rica que es la vida de los seres humanos en sociedades, aunque de forma incompleta, imperfecta e insatisfactoria. Para ello, ella aborda el conjunto de expresiones humanas constantes en las estructuras, en los procesos, en los sujetos, en los significados y en las representaciones. (p.13)

Sin embargo, cabría preguntarse: ¿Cuáles serían los contextos en los que tienen cabida las problemáticas sociales y territoriales que justificarían esa visión conjunta desde la historiografía y el conocimiento geográfico?

El ritmo de las transformaciones internacionales revela, en sus múltiples aspectos, el tránsito hacia una nueva era del devenir humano. Al finalizar el segundo milenio del cristianismo, la clausura de diversos ciclos históricos que se articulan entre sí, tiende a superponer simbólicamente las fechas cronológicas con la culminación de procesos cuyas raíces se detectan en tiempos de larga duración. (Argumedo, 2011, p.259)

Los tiempos de larga duración a los que alude Argumedo (2011), bien podrían emparentarse con el concepto de estructura enunciado por Braudel (1970):
Buena o mala, es ella la que domina los, problemas de larga duración. Los observadores de lo social entienden por estructura una organización, una coherencia, unas relaciones suficientemente fijas entre realidades y masas sociales.

Para nosotros, los historiadores, una estructura es indudablemente un ensamblaje, una arquitectura; pero, más aún, una realidad que el tiempo tarda enormemente en desgastar y en transportar. Ciertas estructuras están dotadas de tan larga vida que se convierten en elementos estables de una infinidad de generaciones: obstruyen la historia, la entorpecen $\mathrm{y}$, por tanto, determinan su transcurrir. Otras, por el contrario, se desintegran más rápidamente. Pero todas ellas, constituyen, al mismo tiempo, sostenes y obstáculos. (p.70)

Las relaciones fijas entre las realidades y las masas sociales a las que se refiere Braudel (1970), se presentan como un eje de sumo interés para explicar los diversos mecanismos bajo los cuales se enmascara la estructura -hasta convertirse por momentos- en un sostén pero también en un obstáculo. Por ejemplo, para Argumedo (2011):

El mundo está afrontando cambios que evocan otras etapas de transición civilizatoria: la caída del Imperio Romano de Occidente, la toma de Constantinopla, la llegada a América, la Revolución Francesa. Estas profundas reformulaciones plantean incertidumbres y serias dificultades para predecir la orientación de los actuales sucesos; y los albores del Tercer Milenio se presentan preñados de paradojas e interrogantes. (p.259)

En la tarea de resolver los interrogantes que se presentan, no puede prescindirse de otras visiones en el intento de explicar la dualidad sosténobstáculo, que caracteriza a la estructura histórica: la perspectiva propuesta por Braudel no se vale solamente de testimonios, sino que además recurre a la geografía, la economía, la antropología y la sociología, insertando de esta manera a las ciencias sociales en la historia, a modo de nuevos colores en el escritorio del historiador (Navarrete Noble, Herrera Mijangos y Salvador Ugalde, 2014). En este aspecto, Barros (2005) indica:

En los últimos dos siglos, el crecimiento exponencial de la población y de los niveles promedio de consumo individual impulsó un vertiginoso incremento de la demanda global de todo tipo de recursos y modificó casi completamente la superficie continental del planeta. La base de la expansión del consumo fue el ritmo explosivo del desarrollo tecnológico, que hizo que por primera vez el género humano produjera impactos globales sobre el planeta, cambiando drásticamente la vida del mismo. (...) Este proceso, que se conoce como cambio climático, es probablemente uno de los desafíos más difíciles para el siglo que se inicia. (p.11) 
Lo más preocupante es que el desequilibrio de la población mundial, a la par del consumo, ha presionado en forma directa al medio ambiente, ocasionado un creciente nivel de contaminantes a escala planetaria. Y aunque el desarrollo tecnológico es necesario y positivo, la contaminación se presenta como un hecho sumamente complejo de resolver, al menos en el corto plazo y desde la intervención de una sola disciplina:

Desde hace tiempo nos hemos acostumbrado a las noticias sobre temas de medio ambiente y a razonar en esos términos. Sin embargo, son poco conocidas las causas principales que desencadenaron esta preocupación por los temas ecológicos. A menudo se piensa -simplificando excesivamente la cuestión- que este interés se originó en el aumento de la contaminación en los países centrales. (...) En realidad, la historia es un poco diferente y tiene otros matices, porque un mero aumento de la contaminación, lo único que hubiera logrado sería un movimiento para ponerle filtros a las chimeneas. (...)

La concepción ecológica pone en cuestión una cierta idea de lo que es la ciencia, entendida como un conjunto de disciplinas separadas unas de las otras. (...) A esta altura, algunos científicos empiezan a ponerse nerviosos ante la dificultad para ubicar ciertos conocimientos en una disciplina o en otra. (Brailovsky, 2012, p.13)

Mientras transcurre tal dificultad en medio de campañas mediáticas y convocatorias en las redes sociales: "El mundo se enfrenta a un peligro aún mayor a largo plazo, el de la sostenibilidad medioambiental. Hace una década, la preocupación por el medio ambiente y la globalización se limitaba sobre todo a los grupos y expertos defensores del entorno. Hoy en día es casi universal" (Stiglitz, 2012, p.43).

¿Es el tiempo de una nueva coyuntura entonces? Braudel (1970) denominó a esta última como "un nuevo modo de relato histórico -cabe decir el «recitativo» de la coyuntura, del ciclo y hasta del «interciclo»- que ofrece a nuestra elección una decena de años, un cuarto de siglo y, en última instancia, el medio siglo" (p.68). Podría afirmarse, que las problemáticas que se han enunciado, son parte de un nuevo relato histórico; y aunque está claro el efecto que tendrán las mismas a escala global, solamente se observan «acontecimientos» aislados, como una derivación forzada de la coyuntura histórica global. "Así, por ejemplo, el término acontecimiento. Por lo que a mí se refiere, me gustaría encerrarlo, aprisionarlo, en la corta duración: el acontecimiento es explosivo, tonante. Echa tanto humo que llena la conciencia de los contemporáneos; pero apenas dura, apenas se advierte su llama” (Braudel, 1970, pp.64-65).
La interpretación del funcionamiento de las estructuras, a la par de las coyunturas y los acontecimientos históricos, se presenta como una alternativa valorable para el abordaje de la realidad social desde lo pedagógico y didáctico; siempre y cuando sean incorporados en el proceso, a aquellos conceptos derivados de la Geografía y las disciplinas sociales. Este viraje en el tratamiento del objeto de estudio de las Ciencias Sociales, aunque revestido de complejidad, no solamente enriquece al ciclo de formación común contemplado para los Profesorados en Historia y en Geografía, sino que además, "al finalizar los dos primeros años de su carrera, los futuros docentes habrán transitado por una formación general con énfasis en aspectos pedagógicos, didácticos y psicológicos y poseerán los conocimientos científicos básicos para iniciar la formación específica en una de las disciplinas" (Res. $\mathrm{N}^{\circ}$ 13259-99. Modificada por Res. $\mathrm{N}^{\circ}$ 3581-00, 1999, p.3). El giro en el enfoque pedagógico y disciplinar es válido y recíproco, indistintamente de la definición profesional por una u otra disciplina: Geografía o Historia.

\section{Interpretar los fenómenos sociales mediante la realidad histórica y las categorías territoriales: aproximaciones teóricas}

Como se ha indicado, el estudio de la realidad social, se presenta como una cuestión compleja al momento de interpretar la dinámica de las sociedades globales; de este modo, la dificultad de abordaje teórico se proyecta directamente en la elección de marcos conceptuales adecuados desde lo pedagógico. En este sentido: "Los hechos y procesos sociales, históricos y espaciales pueden ser considerados según distintas escuelas de pensamiento; cabe esperar, en consecuencia, del futuro docente de Historia o de Geografía, posturas dinámicas, con múltiples perspectivas para la interpretación de la realidad" (Res. $\mathrm{N}^{\circ}$ 13259-99. Modificada por Res. $\mathrm{N}^{\circ} 3581-00,1999$, p.3). Además, y desde el punto de vista disciplinar:

Historia y Geografía han sufrido -en tanto disciplinas- profundos y complejos cambios en la última mitad del siglo. Por una parte, una apertura al análisis de la totalidad de los fenómenos sociales ha superado los tradicionales marcos políticos, militares y diplomáticos; por otra, la expansión de la revolución científico-tecnológica ha generado una nueva organización del territorio y del sistema de relaciones internacionales y ha modificado la valoración de los recursos y del ambiente. Lo que se consideraba inmutable, se concibe, ahora, como una construcción cultural sometida a variaciones en el tiempo y el espacio. (Res. $\mathrm{N}^{\circ}$ 13259-99. Modificada por Res. $\mathrm{N}^{\circ} 3581$ 00,1993, p.3) 
De acuerdo con los fundamentos precedentes, no solo se han superado los enfoques tradicionales producto de la inclusión de los fenómenos sociales en su totalidad, sino que además, se ha sumado un sostenido avance tecnológico, alterando definitivamente las dinámicas territoriales en el orden global. Este proceso, "ha determinado variaciones sustanciales en la concepción de los objetos de estudio, los enfoques y las metodologías de estas disciplinas" (Res. $\mathrm{N}^{\circ}$ 13259-99. Modificada por Res. $\mathrm{N}^{\circ} 3581-00,1999$, p.4). No obstante, es en este estadio de cambios, donde la "realidad histórica" y las "categorías territoriales" se presentan como una alternativa superadora en la interpretación de las sociedades contemporáneas.

Según Gojman (1993): "La complejidad de la realidad histórica supone, para su mejor comprensión, un abordaje analítico, de los factores económicos, políticos, sociales o mentales"(p.56). En el trayecto que traza la autora para su comprensión, expone para el nivel económico, la necesidad de analizar cómo cada sociedad organiza estas actividades con el objetivo de asegurar sus medios de subsistencia y reproducción. En lo social, contempla las formas de organización de las sociedades, quiénes son los actores sociales y como se expresan sus conflictos. En el aspecto político, se analizan las cuestiones relativas al poder, al Estado y a la organización institucional en cada sociedad; y por último, en el nivel de las mentalidades se estudia el conjunto de creencias, saberes, opiniones y valores que identifican la mentalidad del hombre y las sociedades. Estas conforman un conjunto de ideas y valores, "muchas veces contradictorios y cambiantes, que la sociedad acepta -en la mayoría de los casoscomo naturales y obvios" (Gojman, 1993, p.58).

También: "La renovación historiográfica ha rescatado como rasgos predominantes de la realidad histórica la complejidad, el conflicto, el cambio, la permanencia. En este enfoque, el sujeto de la historia se identifica con los hombres y mujeres concretos que desarrollan sus acciones en diferentes planos y dimensiones: económico, social, político, cultural" (Res. $\mathrm{N}^{\circ} 13259-99$. Modificada por Res. $N^{\circ} 3581-00,1999$, p.4). En este orden: "La llamada Escuela de los Annales, fundada en Francia en 1929, desempeñó durante varias décadas del siglo XX un importante papel en la renovación de los estudios de la historia" (Gojman, 1993, p.53). Su influencia se tradujo en un amplio debate historiográfico, en el cuál se aceptaron los aportes de otras ciencias sociales como la economía, la sociología, la psicología, la geografía; apuntando a la recuperación de lo histórico en su totalidad, mediante la vinculación y comunicación de las disciplinas que se ocupaban de las ciencias del hombre (Eggers-Brass, 2006).

Desde otra perspectiva: "En el proceso de conocimiento de la realidad social, la geografía tiene un lugar importante en la medida en que en ella se encuentran el pasado, el presente y el futuro. Como "la geografía se alimenta del movimiento del mundo", la posibilidad de trabajar en el presente intentando entender el mundo real y sus transformaciones es el gran desafío de la disciplina" (Gurevich, 1993, p.83). Bajo el encabezado: «Para situarse mejor», la autora identifica los alcances de las distintas corrientes geográficas, las visiones de la relación naturaleza-sociedad, la dicotomía geografía física-geografía humana, y subraya algunas cuestiones fundamentales:

\begin{abstract}
La geografía, junto con otras materias del área, tiene como objetivo analizar, interpretar y pensar críticamente el mundo social. Por ello, le cabe a nuestra ciencia la tarea de comprender cómo se articulan históricamente la naturaleza y la sociedad, pues las distintas formas de organización espacial son el resultado del particular modo en que las sociedades en determinados momentos históricos se relacionan con la naturaleza, transformándola según sus necesidades e intereses.
\end{abstract}

La geografía utiliza marcos referenciales, conceptos, contenidos, metodologías y técnicas para llevar adelante sus tareas. En algunos casos, toma de otras disciplinas sociales y naturales sus respectivas formas de abordaje de la realidad, y en otros, opera con categorías intelectuales e instrumentales que le son propias. (Gurevich, 1993, p.71)

Respeto a las categorías instrumentales, "la geografía estudia un conjunto integrado de fenómenos que ocurren en períodos de tiempo. (...) Poner una edad a las cosas y a las acciones de las sociedades permite reconstruir los momentos de un proceso" (Gurevich, 1993, p.77). De este manera, las formas del espacio geográfico permiten reconocer la complejidad de los procesos políticos, económicos, sociales y culturales que han tenido lugar en diferentes momentos históricos. Completando la idea; "categorías tales como estructura, proceso, función y forma resultan claves para un análisis del territorio que supone un enfoque espacial del acontecer social. La escala, a su vez, concepto y herramienta propia de esta disciplina, permite una aproximación a lo espacial y la articulación de lo local con los procesos globales" (Res. $\mathrm{N}^{\circ}$ 13259-99. Modificada por Res. $\mathrm{N}^{\circ} 3581-00$, 1999, p.4). Además, en opinión de Gurevich (1998), el papel de los conceptos se constituyen en herramientas básicas de comprensión:

Los conceptos de globalización, gestión de recursos naturales, espacio urbano, cambio tecnológico, reconversión productiva, Estado y políticas públicas adquieren especial relevancia para conocer e interpretar el sentido de los procesos actuales de construcción de los territorios. 
Los conceptos permiten englobar, abstraer y trascender las informaciones particulares convirtiéndose así en herramientas básicas para la comprensión. Los conceptos son construcciones históricas y, por lo tanto, cambiantes. Esto significa que como el mundo cambia, las formas de conocerlo e interpretarlo también lo hacen. (p.160)

Como puede apreciarse, la realidad histórica y las categorías territoriales se vinculan íntimamente ante la necesidad de interpretar y explicar los fenómenos sociales. En atención a lo cual: "Mediante la conjunción de los conocimientos particulares de cada disciplina, los de la formación pedagógica y los de la formación especializada, los futuros docentes de Historia o de Geografía conocerán distintos modelos de enseñanza identificando las concepciones sobre la ciencia, el aprendizaje y la enseñanza escolar que subyacen en los mismos; organizarán secuencias de contenidos y actividades, seleccionarán recursos y estrategias de temas transversales" (Res. $\mathrm{N}^{\circ} 13259-99$. Modificada por Res. $\mathrm{N}^{\circ} 3581-00,1999$, p.4). La selección temática que sigue ilustra a modo de ejemplo -la íntima vinculación existente entre la realidad histórica y las categorías territoriales-; veamos:

Cualquiera que estudie la Tierra aprende pronto que nuestro planeta es un cuerpo dinámico con muchas partes o esferas separadas pero interactuantes. La hidrósfera, la atmósfera, la biosfera, la Tierra sólida y todos sus componentes pueden estudiarse por separado. Sin embargo, las partes no están aisladas. Cada una se relaciona de alguna manera con las otras para producir un todo complejo y continuamente interactuante que denominamos Sistema Tierra.

Un ejemplo sencillo de las interacciones entre distintas partes del Sistema Tierra tiene lugar cada invierno, cuando la humedad se evapora del océano Pacífico y cae después en forma de lluvia en las colinas del Sur de California, provocando deslizamientos destructivos. (...)

Los científicos han reconocido que para comprender mejor nuestro planeta, debemos aprender cómo están interconectados sus componentes (tierra, agua, aire y formas de vida). (...)

Mediante un enfoque interdisciplinario, quiénes practican la ciencia del Sistema Tierra intentan alcanzar el nivel de comprensión necesario para entender y resolver muchos de nuestros problemas ambientales globales. (Tarbuck y Lutgens, 2005, pp.11-12)

De acuerdo con Gurevich (1993): "Así como las formas cambian en el mundo real, las concepciones también lo hacen. Queremos decir que los conceptos no son eternos, sino históricamente construidos" (p.68). Aun cuando en el pensamiento de (Tarbuck y Lutgens, 2005) se identifica una orientación centrada en la Tierra como un Sistema: "Está aconteciendo un proceso de humanización cada vez mayor en el cual la naturaleza se torna cada día más culturizada, más artificializada. A través de la tecnificación, la sociedad impone a la naturaleza sus formas" (Gurevich, 1993, p.69); lo que nos sitúa en otros escenarios posibles para el estudio de la relación naturaleza-sociedad:

La ciencia ambiental es un área interdisciplinaria de estudio que incluye aspectos teóricos y de aplicación del impacto humano en el mundo. Puesto que los humanos generalmente se organizan en grupos, la ciencia ambiental debe tratar la política, la organización social, la economía, la ética y la filosofía. Así, la ciencia ambiental es una mezcla de ciencia tradicional, de valores individuales y sociales, y de conocimiento político.

Aunque la ciencia ambiental, como un campo de estudio, está evolucionando, continúa arraigada en la historia de los inicios de la civilización. Muchas culturas antiguas expresaron una veneración por las plantas, los animales y las características geográficas que les proporcionaron alimento, agua y trasporte. Estas características todavía son apreciadas por muchas personas modernas. (Enger y Smith, 2006, p.5)

Enger y Smith (2006) colocan el acento en la interdisciplinariedad, el impacto humano y la dimensión etnográfica en relación con el medio ambiente. Y esta última consideración, acerca de la valoración de ciertas plantas, animales y paisajes, resultan de particular interés para valorar los principales medios de subsistencia, sobre todo, el acceso al agua y lo que este preciado recurso ha significado para las antiguas civilizaciones, y lo que significa aún hoy, para la población mundial. Las consideraciones establecidas orientan una apertura hacia los procesos históricos; y a decir verdad: "Para el conocimiento histórico, toda la experiencia de los hombres es significativa: incluye tanto la forma como los hombres resolvieron y resuelven sus necesidades básicas (alimentación, abrigo, trabajo) como las diversas maneras de organizar sus familias, de educar a sus hijos, de construir sus viviendas, de expresar su religión" (Gojman, 1993, p.55). También surgen otras inquietudes relacionadas con el poder político, las ideologías y las variables económicas que interactúan con la dinámica de las sociedades y los territorios a escala global:

Se presentan ante nuestros ojos diversos caminos de evolución potencial de la historia humana y es imposible predecir las nuevas orientaciones que predominen; hacia que mundo nos dirigimos; cuáles serán los conflictos y los acuerdos que habrán de gestarse; los sujetos históricos que protagonicen la etapa que se inicia. Las síntesis que en el futuro puedan emerger de las tendencias de articulación continental entre los distintos países del Norte, de las realidades y alternativas de las regiones del Sur; de las fusiones entre los 
anteriores socialismos y las economías de mercado; de las tradiciones políticas de Occidente con las de Oriente y las del Sur; de las demandas nacionales y democráticas con las reivindicaciones sociales; todo ello conjugado con la globalización de las comunicaciones y los flujos informativos en tiempo real y con los trastocamientos que conllevan los nuevos paradigmas productivos y de administración económica y social; han de dar lugar al surgimiento de nuevas realidades cuyos rasgos seguramente desbordarán las tradicionales denominaciones de capitalismo y socialismo. (Argumedo, 2011, p.296)

La cita anterior corresponde al trabajo de Alcira Argumedo Los Silencios y las Voces de América Latina: Notas sobre el pensamiento nacional y popular (2011); si bien la autora no hace alusión al medio ambiente o la relación naturaleza-sociedad, sus argumentaciones e interrogantes sobre las fusiones político-económicas, los flujos de información y la evolución de la historia de la humanidad -conllevan intrínsecamente en su construcción discursiva- la anuencia de ciertos parámetros fundamentales acerca de los efectos del impacto humano sobre los conjuntos naturales y su proyección territorial en el orden global. De acuerdo con Gurevich (1993): "La realidad, que es compleja, múltiple y contradictoria, nos acerca a diario situaciones problemáticas que merecen constituirse en objeto de estudio" (p.65). Por lo tanto, las argumentaciones de Tarbuck y Lutgens (2005), Enger y Smith (2006), y Argumedo (2011) son factibles de alinearse con los requisitos que esgrime Gurevich (1993) respecto al abordaje de la realidad social. En opinión de esta autora: "La relación entre geografía y el problema de la relevancia de su estudio puede resolverse al ocuparnos de problemas territoriales actuales. Esto implica recortar una parcela de la realidad que se presenta como significativa, trascendente, conflictiva, y estudiarla en sus múltiples dimensiones" (Gurevich, 1993, p.65). Y en cualquiera de los asuntos citados, es factible de llevarse a cabo. En términos pedagógicos, "los contenidos no vienen dados a priori siguiendo el orden del programa, sino que serán aquellos necesarios para explicar la situación seleccionada" (Gurevich, 1993, p.65).

\section{Planteo de un esquema de referencia pedagógico para el ciclo de formación común de los profesorados en historia y geografía}

Tras reflexionar sobre las complejidades que conlleva el estudio de la realidad social, y habiendo expuesto algunos alcances teóricos sobre la realidad histórica y las categorías territoriales, toca formular a continuación -un esquema de referencia pedagógico- cuyas relaciones conceptuales articulen el estudio de los procesos históricos y los espacios geográficos, considerando a la complejidad, el conflicto, el cambio y la permanencia como rasgos de la «realidad histórica», y a la estructura, el proceso, la función y la forma como «categorías clave del análisis territorial». Respecto a la primera: "el sujeto de la historia se identifica con los hombres y mujeres concretos que desarrollan sus acciones en diferentes planos y dimensiones: económico, social, político, cultural. (...) En cuanto a Geografía, (las) categorías (...) resultan claves para un análisis del territorio que supone un enfoque espacial del acontecer social" (Res. $\mathrm{N}^{\circ} 13259-99$. Modificada por Res. $\mathrm{N}^{\circ} 3581-00$, 1999, p.4).

A tal fin se han seleccionado: 1) Los Núcleos de Aprendizajes Prioritarios de Ciencias Sociales [nap] (Ministerio de Educación, 2012); y 2) El Proyecto Arte e Imágenes Territoriales. Coloquio de los artistas contemporáneos con el Medio Ambiente (Avegno, Alonso Cabral, Duperré y Morales, 2010).

A continuación, la tabla 1, muestra un Esquema de temas prioritarios, para una posible "agenda de problemas socioterritoriales del mundo actual" (Fernández Caso, 2007, p.27). La «dimensión» indica una variable de análisis de los territorios en lo político, sociodemográfico, ambiental, cultural y económico derivada de los [nap]; la «Agenda» recoge, por otra parte, algunas de las problemáticas que exploran Avegno et al. (2010) en Arte $e$ Imágenes Territoriales. Sus contenidos sintetizan las principales cuestiones que han venido desarrollándose, y constituyen una guía para trabajar el Espacio de la Orientación y el Espacio de la Práctica durante el Ciclo de Formación Común de los Profesorados en Historia y en Geografía: Perspectiva Espacio Temporal de Argentina y América; Perspectiva Espacio Temporal Mundial; Antropología; Integración Areal I; Espacio de la Práctica Docente I. Pudiendo hacerse extensiva su aplicación al Segundo Año de la Carrera en Geografía: Perspectiva Ambiental I; Perspectiva Social; Economía; Sociología; Historia I; Integración Areal II; Espacio de la Práctica Docente II (Escuela Normal Superior № 109 - Instituto Nacional de Formación Docente $N^{\circ} 109,2018$ ).

Evaluemos seguidamente, que significaciones se desprenden del planteo realizado, y cuales son sus alcances para el estudio de la realidad social. 
Tabla 1. Esquema de referencia pedagógico para el estudio de la «Realidad social».

\begin{tabular}{|c|c|}
\hline Dimensión Territorial & Agenda \\
\hline 1. Ambiental & $\begin{array}{l}\text { 1.1 Procesos } \\
\text { geológicos y } \\
\text { geomorfológicos } \\
\text { del Planeta } \\
\text { Tierra } \\
1.2 \\
\text { Funcionamiento } \\
\text { climático en } \\
\text { nuestro Planeta } \\
1.3 \text { Causas de la } \\
\text { degradación } \\
\text { Ambiental "Nuestro } \\
1.4 \text { Futuro Común": } \\
\text { Informe } \\
\text { Brundland }\end{array}$ \\
\hline $\begin{array}{l}\text { 2. Económica } \\
\text { 3. Política }\end{array}$ & $\begin{array}{l}2.1 \text { Sectores } \\
\text { Económicos } \\
2.2 \quad \text { Circuitos } \\
\text { Productivos } \\
\text { 3.1 Globalización: } \\
\text { Cara y } \\
\text { Contracara de un } \\
\text { Nuevo Mapa } \\
\text { Mundial }\end{array}$ \\
\hline $\begin{array}{l}\text { 4. Cultural } \\
\text { 5. Sociodemográfica }\end{array}$ & $\begin{array}{l}\text { 4.1 Cuestiones } \\
\text { Demográficas } \\
\text { 5.1 Políticas } \\
\text { Gubernamentales } \\
\text { aplicadas a la } \\
\text { Población }\end{array}$ \\
\hline
\end{tabular}

Fuente: Adaptado de Ministerio de Educación, Presidencia de la Nación, [nap] Ciencias Sociales, 2012; y de Avegno, Alonso Cabral, Duperré y Morales, Arte e Imágenes Territoriales, 2010.

Para la Dimensión ambiental del territorio -los [nap]- plantean la necesidad de conocer los modos de valoración que las sociedades hacen de los conjuntos ambientales; la explicación de los tipos de manejo de los recursos naturales; la interpretación de la tensión entre los componentes económicos, físico-naturales, sociales, políticos y culturales; y la reflexión sobre los riesgos y vulnerabilidad frente a los desastres y catástrofes (Ministerio de Educación, 2102). Estos núcleos pueden reconocerse en la propuesta Arte e Imágenes Territoriales en los bloques temáticos: Procesos geológicos y geomorfológicos del Planeta Tierra y Funcionamiento climático en nuestro Planeta. En el primero, los autores se remiten a los procesos de cambio del planeta Tierra a través del tiempo; la explicación de las eras geológicas; la incidencia del vulcanismo en los territorios, los conceptos de convergencia y divergencia; las geoformas de la superficie terrestre; y la capacidad de respuesta de las sociedades ante los embates ambientales, identificando el grado de vulnerabilidad ante aquellos. Merece especial atención el desarrollo de la problemática sobre el recurso: agua y su contextualización mediante la instalación de Hwang Jongmyung denominada Swimmers (Bienal de Valencia, 2005), en la que "una serie de figuras humanas fragmentadas de nadadores, emergen de un piso desprovisto de agua como una gran pileta vacía, aludiendo a la necesidad vital de este recurso" (Avegno et al., 2010, p.25).

En lo que hace al funcionamiento climático (segundo bloque temático), se definen los conceptos de temperatura, presión atmosférica, humedad, vientos; y las causas de degradación ambiental. Sobre esta temática, la exposición «Intemperie-El fin del tiempo», que tuvo lugar en San Pablo en 2009 como anticipo de la «Bienal del Fin del Mundo» en Ushuaia (segunda edición), reunió obras de artistas diversos, cuya preocupación acerca de los problemas climáticos, se plasmó en vídeos y fotografías de grandes dimensiones, expresando el distanciamiento del hombre ante las transformaciones del medio ambiente a escala mundial (Avegno et al., 2010). En el encuadre de estas problemáticas, los autores ejemplifican los derrames petroleros y las consecuencias de los desechos contaminantes en el medio ambiente, mediante la instalación Los centinelas (2002) de la artista plástica Nora Correas, "en la cual utiliza como soporte una pecera de vidrio transparente donde se hace evidente la contraposición entre la pureza del agua y la viscosidad del petróleo. Mientras que en la parte superior de la pecera, una serie de calaveras en resina ofician como centinelas y protectores ante los conflictos bélicos y controversias que generan la posesión de estos recursos en los diferentes países" (Avegno et al., 2010, p.31).

Figura 1. Jongmyung, Hwang. Swimmers, instalación Bienal de Valencia, 2005. - Figura 2. Correas, Nora. Los Centinelas, 2002. Instalación, vidrio, acero inoxidable, petróleo ,agua y resina, 221 x 115 x $55 \mathrm{~cm}$.
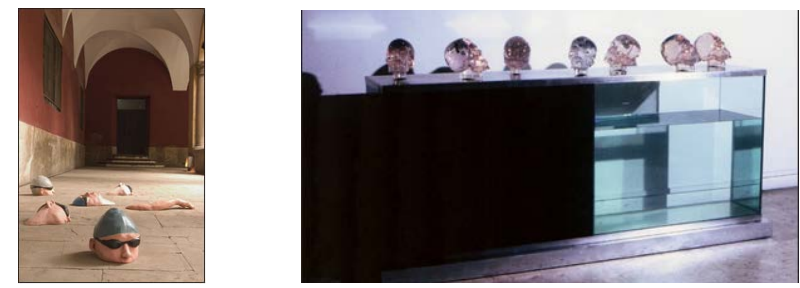

Fuente: adaptado de Arte e Imágenes Territoriales, Universidad del Salvador, 2010.

En la Dimensión económica y política, los requerimientos pedagógicos [nap] apuntan al conocimiento de la organización territorial de la 
producción en el marco de la economía globalizada; la explicación de las transformaciones tecnoproductivas; la dinámica del trabajo; la interpretación de las redes y flujos de transporte; y el reconocimiento de los consensos y conflictos en la conformación de sociedades democráticas y participativas. En este caso, Avegno et al., (2010) en el capítulo Procesos de Organización Territorial en el Contexto Global, describen los factores que han dado impulso a la expansión del intercambio territorial a través de las redes de comunicación y las nuevas tecnologías; para ejemplificar dicho proceso, distinguen a la instalación Galaxias (Bienal de Venecia 2009): "la propuesta artística de Tomás Saraceno, ofrece una mirada que se destaca por la relación que establece entre tecnología, geopolítica y arte. Así, en una de sus obras (instalación con cuerdas elásticas) las Galaxias van formándose a lo largo de filamentos, como gotitas en los hilos de una telaraña. Una red en la que se superponen y articulan diferentes realidades posibles que dan forma a un mundo complejo en que nos toca vivir" (Avegno et al., 2010, p.41).

El funcionamiento de los sectores económicos, actividades y circuitos productivos, cierran la Dimensión 2; en tanto que el análisis de la Globalización: cara y contracara de un nuevo mapa mundial, introduce la Dimensión Política de los Territorios; aquí se establecen los contrastes en el acceso a los recursos naturales, la capacidad productiva, y el grado de desarrollo tecnológico, en cada una de las regiones del planeta (Avegno et al., 2010). "Estas cuestiones pueden relacionarse con la obra de Paula Diringer, Positivo-Negativo; la artista nos remite al rol emblemático que tuvieron las instituciones en los Estados de Bienestar en el S. XX, su posterior desdibujamiento y fragmentación a causa de los procesos políticos que tuvieron lugar a partir de la década del 90, no sólo en Argentina, sino también en la (...) mayoría (...) de los países latinoamericanos" (Avegno et al., 2010, p.45).

Figura 3. Saraceno, Tomás. Galaxias, instalación con cuerdas elásticas Bienal de Venecia 2009. - Figura 4. Diringer, Paula. Positivo - Negativo, 2009, bordado s/ bastidores entelados, $140 \times 140 \mathrm{~cm}$.
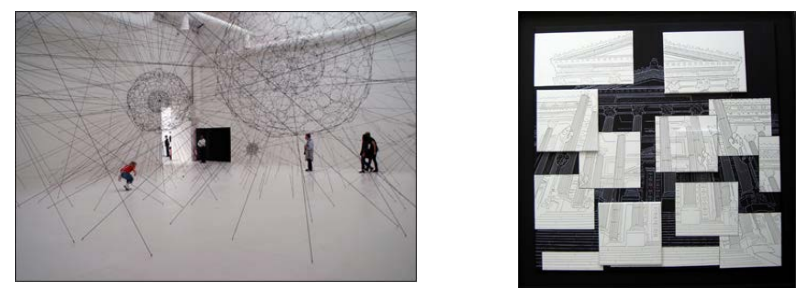

Fuente: adaptado de Arte e Imágenes Territoriales, Universidad del Salvador, 2010.

En cuanto a las Dimensiones Cultural $y$ Sociodemográfica, el capítulo: Desigualdad, pobreza y exclusión social (Avegno et al., 2010, p.49), analiza las Cuestiones demográficas y las Políticas gubernamentales aplicadas a la población, la eliminación de residuos y la demanda de mano de obra que ingresa a los centros urbanos de otras ciudades o de las áreas rurales.

Figura 5. Meijide, Jorge. Carton Road, 2005, objeto, madera, látex, acrílico, 60 × 197 x $36 \mathrm{~cm}$.

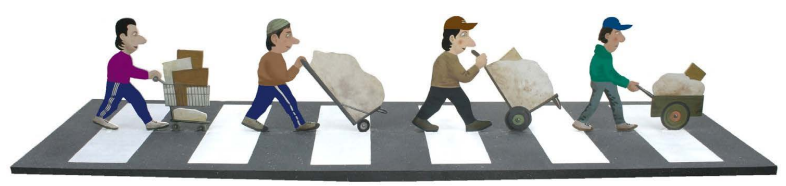

Fuente: adaptado de Arte e Imágenes Territoriales, Universidad del Salvador, 2010.

Los [nap] contemplan para estas dimensiones: el conocimiento de la estructura y la dinámica de la población; la comprensión del crecimiento demográfico; el análisis de las nuevas configuraciones urbanas; el reconocimiento de la desigualdades en las condiciones de vida; y el respeto y valoración de la diversidad cultural.

Por ejemplo, "la obra Carton Road (2005), del artista plástico Jorge Meijide, presenta un grupo de personajes que transitan diariamente las calles, mostrando las actividades que en las últimas décadas se han hecho más evidentes en las grandes ciudades; nos referimos a vastos sectores de población que a través de la recolección y venta de cartones en desuso y otros elementos, logran un ingreso monetario para poder subsistir diariamente" (Avegno et al., 2010, pp. 51-52).

Otras de las problemáticas se centra en los desplazamientos demográficos, el conflicto en Medio Oriente y los contrastes entre las áreas receptoras y expulsoras de población: "La mirada de la artista contemporánea Mirta Kupferminc, a través de la serie La piel de la memoria (2009), sintetiza en las obras El mapa, La línea del corazón y La mano del inmigrante, el recorrido bordado en la piel de las manos de todos aquellos que deben construir lejos de su lugar de origen, no sólo su historia sino también su identidad" (Avegno et al., 2010, p.57).

Figura 6. Kupferminc, Mirta. El mapa (de la serie "La piel de la memoria"), 2009, papel fotográfico y bordado, $30 \mathrm{x}$ $30 \mathrm{~cm}$. - Figura 7. Kupferminc, Mirta. La mano del inmigrante (de la serie "La piel de la memoria"), 2009, papel fotográfico y bordado, 30 x $30 \mathrm{~cm}$.
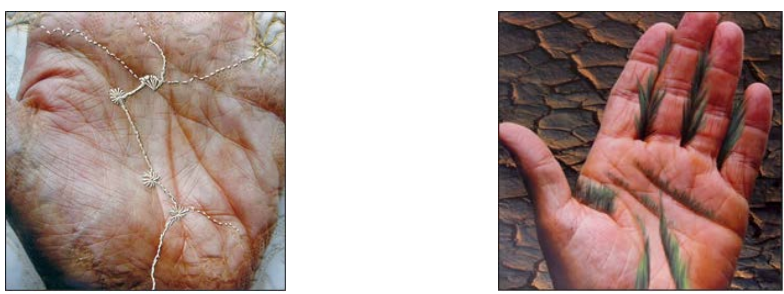

Fuente: adaptado de Arte e Imágenes Territoriales, Universidad del Salvador, 2010. 


\section{Consideraciones finales}

En primer término, los «nap» para ciencias sociales, "serán un organizador de la enseñanza orientada a promover múltiples y ricos procesos de construcción de conocimientos" (Ministerio de Educación, 2012, p.7). Aplicados al «Campo de Formación General y Ciclo Orientado de Educación Secundaria», estos Núcleos "integran los saberes de la formación general que todos los estudiantes deben aprender en su escuela secundaria" (Ministerio de Educación, 2012, p.12). Indudablemente se deben tener en cuenta, a los fines de lograr su articulación con la Formación Docente de Grado en Historia y Geografía, ya que el contexto de actividad profesional del futuro docente, tendrá lugar en el Campo General y Ciclo Orientado de Educación Secundaria.

El segundo aporte seleccionado pone en discusión el accionar del hombre y su protagonismo en los procesos de cambio, e identifica los principales emergentes medioambientales y sociales bajo la lupa del arte contemporáneo. Fue realizado como Proyecto Final de Grado (libro digital) en el marco de la Carrera Gestión e Historia de las Artes de la Universidad del Salvador. Su principal objetivo consiste en "demostrar el modo en que los artistas plásticos plantean, denuncian y trabajan sobre la tierra, los problemas ambientales y geográficos" (Facultad de Historia, Geografía y Turismo, Universidad del Salvador, 2010). Desde el punto de vista temático, acerca al lector un inventario de problemas sociales y territoriales vinculados con el Medio ambiente, los Procesos de organización territorial en el Contexto global y la Desigualdad, Pobreza y Exclusión social. La proyección de aquellos, tiene una actualidad vital, ya que los "Temas Especiales y Programas Mayores" (UNESCO, 2017) de la Organización de las Naciones Unidas para la Educación, la Ciencia y la Cultura [UNESCO], no solamente incluyen a las cuestiones citadas en su agenda, sino que además, fomenta la creatividad y las manifestaciones del arte contemporáneo como indicadores de enriquecimiento colectivo:

En el mundo interconectado en el que vivimos, es fácil constatar que la cultura tiene el poder de transformar las sociedades. Sus diversas manifestaciones, que abarcan desde los más preciados monumentos históricos y museos hasta los ritos tradicionales y el arte contemporáneo, enriquecen nuestro día a día de múltiples maneras. El patrimonio constituye una seña de identidad y favorece la cohesión de las comunidades que no asimilan bien los cambios rápidos o que sufren el impacto de la crisis económica. La creatividad contribuye a la edificación de sociedades abiertas, inclusivas y pluralistas. El patrimonio y la creatividad contribuyen a la construcción de sociedades del conocimiento dinámicas, innovadoras y prósperas. (UNESCO, 2018)
Y en concordancia con estos indicadores, Arte $e$ Imágenes Territoriales realiza "un aporte creativo al contexto pedagógico; (al estimar) que hoy más que nunca, es necesaria la creatividad y la búsqueda de soluciones alternativas ante los problemas $\mathrm{y}$ conflictos que transita la humanidad" (Avegno et al., 2010, p.11). En virtud de ello: los propósitos y funciones para la Formación Docente de Grado destacan, como una de las competencias requeridas por el rol del educador, al "conocimiento de los marcos teóricos que sustentan la práctica y reflexión acerca de ésta para la confrontación y producción de nuevos marcos que sirvan para transformarla" (Res. N ${ }^{\circ}$ 13259-99. Modificada por Res. $\quad \mathrm{N}^{\circ}$ 3581-00, 1999, p.3); y en dicha competencia, puede mencionarse a la creatividad como una de cualidades que intervienen durante el proceso «práctica-reflexión» educativa.

Por último, y en anuencia con Marazzi y Pizzano (2011): "El arte en su conjunto como conformador necesario de la cultura, es la herramienta $y$, o el escape del ser humano a las diferentes pulsiones cotidianas, comenzando hace miles de años en pequeños reductos, y concluyendo hoy en lugares destinados al albergue de las diferentes expresiones artísticas" (p.18). En este proceso histórico, ha sido la técnica la que ha desempeñado un rol esencial: "Por ejemplo, los utensilios de piedra o el dominio del fuego constituyen las tecnologías fundamentales indisociables del desenvolvimiento de la especie humana. Hoy en día, las Tecnologías de la Información y la Comunicación (...) representan el elemento clave en el cambio hacia la sociedad de la información" (Watzlawik y Blanco, 2011, p.22). Este avance sostenido de las nuevas tecnologías se ha infiltrado como una necesidad cotidiana en todos los ámbitos de la sociedad contemporánea, lo que ha colocado a los ámbitos de enseñanza y aprendizaje en una situación compleja por el cambio sustancial en los modos de comunicación. Por añadidura, y "refiriéndonos a los últimos dos siglos pasados XIX y XX, este proceso de interacción y adaptación humana a la innovación tecnológica nunca fue tan radical y dramático como en el presente" (Watzlawik y Blanco, 2011, p.22), sobre todo para las comunidades educativas, dado que: "Toda sociedad ha buscado que las generaciones futuras adquieran los conocimientos acumulados para que se adapten a la vida; la educación ha sido un medio para que se reproduzcan la cultura y la sociedad de manera continua" (Watzlawik y Paglialunga, 2011, p.7).

\section{Agradecimientos}

A los artistas plásticos que intervinieron en el Proyecto: Arte e Imágenes Territoriales (2010) de la Universidad del Salvador, por enriquecer a través de sus obras, la propuesta del presente artículo. 


\section{Referencias}

Argumedo, A. (2011). Los silencios y las voces en América Latina. Notas sobre el pensamiento nacional y popular. Buenos Aires, Argentina: Ediciones del Pensamiento Nacional. Ediciones Colihue S.R.L., 259-296.

Avegno, M. C., Alonso Cabral, R., Duperré G. N. y Morales, S. (2010). Arte e Imágenes Territoriales. Coloquio de los artistas contemporáneos con el Medio Ambiente (tesis de grado). Universidad del Salvador, Buenos Aires, Argentina, 11-57.

Barros, V. (2005). El Cambio Climático Global ¿Cuántas catástrofes antes de actuar? Buenos Aires, Argentina: Libros del Zorzal, 11.

Brailovsky, A. E. (2012). Ésta, nuestra única Tierra. Introducción a la Ecología y Medio Ambiente. Provincia de Buenos Aires, Argentina: Editorial Maipué, 13.

Braudel, F. (1970). La Historia y las Ciencias Sociales. Madrid: Alianza Editorial, S. A., 64-70.

De Souza Minayo, M. C. (Organizadora), Ferreira Deslandes, S., Cruz Neto, O., y Gomes, R. (2007). Investigación social: teoría, método y creatividad. Buenos Aires: Lugar Editorial, 13.

Durán, D. (1996). Geografía y trasformación curricular. Buenos Aires: Lugar Editorial.

Eggers-Brass, T. (2012). Historia IV: Historia reciente en la Argentina. Provincia de Buenos Aires: Editorial Maipue, 24.

- (2006). Historia Argentina: Una mirada crítica. Provincia de Buenos Aires: Editorial Maipue.

Enger, E. D. y Smith B. F. (2006). Ciencia ambiental. Un estudio de interrelaciones. Ciudad de Buenos Aires, Argentina: McGraw-Hill/ Interamericana Editores.

Escuela Normal Superior № 109 - Instituto Nacional de Formación Docente (2016). Plan de Estudios: Profesorado en Geografía Res. No 26/03. Recuperado de https://isfd109bue.infd.edu.ar/sitio/index.cgi?wid_seccion=3\&wid_item $=6$

Feinmann, J. P. (2011). La filosofía y el barro de la historia. Del sujeto cartesiano al sujeto absoluto comunicacional. Ciudad Autónoma de Buenos Aires: Grupo Editorial Planeta S. A. I. C.

Fernández Caso, M. V., (2007). Discursos y prácticas en la construcción de un temario escolar en Geografía. En: Fernández Caso, M. V. y Gurevich, R. (Coordinadoras), Geografía: nuevos temas, nuevas preguntas. Un temario para su enseñanza (p-27, Cap. I). Buenos Aires: Editorial Biblos.

García, P., Iaíes, G. y Segal, A. (1993). Que enseñamos cuando enseñamos Ciencias Sociales. En: Finocchio, S. (Coordinadora), Enseñar Ciencias Sociales (p-33, Cap. III). Buenos Aires: Editorial Troquel S. A.

Gojman, S. (1993). La historia: una reflexión sobre el pasado. Un compromiso con el futuro. En: Aisenberg, B. y Alderoqui, S. (Comps.), Didáctica de las ciencias sociales: Aportes y reflexiones (pp.53-58, Cap. 2). Buenos Aires: Paidós.

Gurevich, R. (1993). Un desafío para la geografía: explicar el mundo real. En: Aisenberg, B. y Alderoqui, S. (Comps.), Didáctica de las ciencias sociales: Aportes y reflexiones (pp.65-83, Cap. 3). Buenos Aires: Paidós.

- (1998). Conceptos y problemas en geografía. Herramientas básicas para una propuesta educativa. En: Aisenberg, B. y Alderoqui, S. (Comps.), Didáctica de las ciencias sociales II: Teorías con prácticas (p.160, Cap. 6). Buenos Aires: Paidós.

Klimovsky, G. e Hidalgo, C. (2012). La inexplicable sociedad. Cuestiones de epistemología de las Ciencias Sociales. Ciudad Autónoma de Buenos Aires: A-Z editora S.A., 20-24.

Marazzi, R. A. y Pizzano, P. V. (2011). Ciencias Sociales ¿Ciencia, Arte y Técnica? Buenos Aires: Nueva Asociación Capacitación educativa Responsable [N.A.C.E.R], 18.

Ministerio de Educación. Presidencia de la Nación (2012). Núcleos de Aprendizajes Prioritarios [nap]. Ciencias Sociales. Historia, Geografía, Economía. Campo de Formación General. Ciclo Orientado Educación Secundaria. Buenos Aires: Consejo Federal de Educación [cfe], 7-12.

Navarrete Noble, R. E., Herrera Mijangos, S. N. y Salvador Ugalde, K. I. (2014). La historia de larga duración de Fernand Braudel. En: Boletín Científico de la Escuela Superior Atotonilco de Tula. Universidad Autónoma del Estado de Hidalgo. Secretaria de Desarrollo Internacional, 1 (2). Recuperado de https://www.uaeh.edu.mx/scige/boletin/atotonilco/n2/e3.html

Provincia de Buenos Aires. Poder Ejecutivo (1999). Res. $N^{\circ} 13271-99$. Modificada por Res. $N^{\circ} 3581-00$. Primera Parte: Estructura General, 5-7.

Provincia de Buenos Aires. Poder Ejecutivo (1999). Res. $N^{\circ} 13271-99$. Modificada por Res. $N^{\circ} 3581-00$. Sexta Parte: Profesorado de Tercer Ciclo de la EGB y de la Educación Polimodal en Geografía e Historia. Recuperado de http://servicios2.abc.gov.ar/lainstitucion/organismos/consejogeneral/disenioscurriculares/superior/g eografia/13259-99modif-por-3581-00-geografia.pdf, 3-4.

Stiglitz, J. E. (2012). Cómo hacer que funcione la globalización. Buenos Aires: Taurus, 43.

Tarbuck, E. J. y Lutgens F. K. (2005). Ciencias de la Tierra. Una introducción a la geología física. Madrid: Pearson Educación S. A., 11-12. 
UNESCO (2018). Proteger el patrimonio y fomentar la creatividad. Recuperado de https://es.unesco.org/themes/protecting-our-heritage-and-fostering-creativity

- (2017). Construir la paz en la mente de los hombres y de las mujeres. Programas mayores. Temas especiales. Recuperado de http://www.unesco.org/new/es/unesco/themes/

Universidad del Salvador, Facultad de Historia, Geografía y Turismo (2018). Materia Proyecto de Investigación II. Recuperado de http://hgt.usal.edu.ar/hgt/materia-proyectos-investigacion-2

Watzlawik, L. y Blanco, A. (2011). TIC y Ciencias Sociales, derribando mitos. Buenos Aires: Nueva Asociación Capacitación educativa Responsable [N.A.C.E.R], 22.

Watzlawik, L. y Paglialunga, V. (2011). Medios audiovisuales y Ciencias Sociales. Buenos Aires: Nueva Asociación Capacitación educativa Responsable [N.A.C.E.R], 7. 